\title{
Complementary health insurance, out- of- pocket expenditures, and health services utilization: A population- based survey
}

\author{
Enayatollah Homaie Rad ${ }^{1}$, Zahra Kavosi², Mohammad Taghi Moghadamnia ${ }^{3}$, Masoud Arefnezhad ${ }^{4 *}$, \\ Masoumeh Arefnezhad ${ }^{4}$, Banfashe Felezi Nasiri ${ }^{1}$
}

Received: 10 Mar 2017

Published: 9 Sep 2017

\begin{abstract}
Background: Studies have shown that people using complementary health insurances have more access to health services than others. In the present study, we aimed at finding the differences between out- of- pocket payments and health service utilizations in complementary health insurances (CHIs) users and nonusers.

Methods: Propensity score matching was used to compare the 2 groups. First, confounder variables were identified, and then propensity score matching was used to compare out- of- pocket expenditures with dental, general physician, hospital inpatient, emergency services, nursing, midwifery, laboratory services, specialists and rehabilitation services utilization.

Results: Our results revealed no significant differences between the 2 groups in out- of- pocket health expenditures. Also, the specialist visits, inpatient services at the hospital, and dental services were higher in people who used CHIs compared to nonusers.

Conclusion: People did not change their budget share for health care services after using CHIs. The payments were equal for people who were not CHIs users due to the increase in the quantity of the services.
\end{abstract}

Keywords: Complementary insurances, Propensity scoring matching method, Out- of- pocket expenditures, General physicians, Dental services, Specialists

Copyright $\odot$ Iran University of Medical Sciences

Cite this article as: Homaie Rad E, Kavosi Z, Moghadamnia MT, Arefnezhad M, Arefnezhad M, Felezi Nasiri B. Complementary health insurance, out-of-pocket expenditures, and health services utilization: A population-based survey. Med J Islam Repub Iran. 2017 (9 Sep);31:59. https://doi.org/10.14196/mjiri.31.59

\section{Introduction}

Health insurance is one of the most important resources of health care finance. In the last decades, by improving health technology, health care expenditures had been increased and insurance coverage became more important in protecting people from suffering from catastrophic health expenditures (1). However, there were some barriers in the way to achieve comprehensive coverage of health insurances. For example, some health services such as dental care have very high price elasticity (2). These services cannot be covered by health insurances easily and impose financial pressure to the insurers due to their high costs

Corresponding author: Masoud Arefnezhad, arefnezhad67@yahoo.com

1. Guilan Road Trauma Research Center, Guilan University of Medical Sciences, Rasht, Iran.

2. School of Health Management and Informatics, Shiraz University of Medical Sciences, Shiraz, Iran

3. School of Public Health, Tehran University of Medical Sciences, Tehran, Iran.

4. School of Health, Zabol University of Medical Sciences, Zabol, Iran.
(3). Complementary health insurances (CHIs) are a solution to these variations in expenditures. CHIs help to financially protect people in 2 ways: (1) covering new services, and (2) decreasing deductibles and franchises of health services, which are covered by basic programs (4).

The effects of comprehensive coverage are studied from both health and expenditures aspects. From the health aspect, CHI helps abolish financial obstacles of access to health services and improves people's health and wellbeing $(5,6)$. It also helps to promote a healthier society by utilization of more services. On the other hand, CHI caus-

$\uparrow$ What is "already known" in this topic:

Complementary health insurance is a means to decrease outof- pocket expenses and increase health service utilizations in the world. The amount of service utilization after covering by complementary health insurance is related to the socioeconomic and cultural factors of each country.

$\rightarrow$ What this article adds:

Complementary health insurance in Iran did not change outof- pocket expenses because people did not change the share of health care expenses in the family budget, and they decided to use more health care services instead. 
es an increase in health expenditures by covering more expensive services and sometimes exploiting services that are not essential; this has been called moral hazard in the literature (7-9).

Nowadays, the lack of an effective financial system in health- related spending has become an important issue, especially in less developed countries. High amount of out- of- pocket payments is one of the consequences of this deficiency. In some cases, the proportion of health payments in family's budget is so high that the family suffers from catastrophic costs (10). CHIs can support families by distributing the financial risk of health to a large number of members and protect families from falling down to poverty and the financial disaster of diseases (6, 10-12). Iran health care system is insurance based. Three health insurance companies have the highest health insurance coverage in the country: Iran Health Insurance Organization, Social Security Organization, and Armed Forces Health Insurance (13). Before the 2014 reform of health care system, which was called "Health Sector Evolution", near 9 million people in Iran were not covered by any health insurance and the share of out- of- pocket health expenditures from total health expenditures was more than 50\%. However, after the reform, the government tried to provide insurance for the uncovered population $(14,15)$.

Different studies revealed that the increase of coverage will decrease the amount of out- of- pocket payments and catastrophic costs and increase utilization of services (16). Despite many studies on the effects of health insurance on utilization of services and health expenditures, few studies have been conducted in Iran on these issues. In this study, we aimed at finding the effects of CHIs on the out- of- pocket health expenditures and health utilization in Iran. We compared out- of- pocket health expenditures between the 2 groups: people who are under the coverage of CHIs, and others. Also, we compared their utilization of different services (dental, general physician, hospital inpatient, medical emergency, nursing and midwifery, laboratory, specialists, and rehabilitation services). Shiraz is a city in South of Iran with high- ranked hospitals and its population was 1.461 million in 2012. The pilot of urban family plan has been implemented in Shiraz since 2012. Iran has 3 major health insurance companies: Social Security Insurance, Iranian Health Insurance Organization, and Military Services Insurance Organization. Due to confounding bias, a matching estimator approach was used to compare the 2 groups.

\section{Methods}

\section{Study design}

In this cross- sectional study, data had been derived from a previously-gathered data, which had already been surveyed in Shiraz, Iran. All the participants were older than 18 years and at least covered by 1 basic health insurance. The sample size of the original study was 1610 individuals and from them, 1354 were selected. The missing data included the data on persons who did not specify whether they had complementary health insurance or not; and the missing data were not systematic. The survey de- sign and sample selection in the original data selection were done as follow:

1. The city was divided into 9 regions, each of which had different socioeconomic status.

2. The study sample was calculated for each region proportionally.

3. In each region, 10 blocks were selected randomly using municipality maps.

4. In each block, a number among 0 to 9 was selected randomly. The selected number was the first household. For the second household, we added the number of the first household by 10. For example, if the first house was the 6 th in the block, the second would have been the 16 th and so on. We continued the process until the requisite sample was selected.

5. To avoid selection bias, KISH method was used in each household.

A checklist was designed to collect the data, and 10 interviewers were trained to fill in the checklist. The expenditures and utilization of health services for a month were gathered. In each stage, $5 \%$ of data were extracted and the accuracy of sampling was checked by phone to assess the collected data and the households' responses.

\section{Econometrics Method}

Data collection was not applicable in this study, and previously gathered data were used. These data were not matched by confounding factors, and propensity score matching was used to achieve unbiased results(17). Propensity score method allows to match previously gathered data easily and was used to compare the 2 groups. First, confounder variables were identified using probit regression. In the probit regression, the dependent variable was $\mathrm{CHI}$ users with the value of 1 , and nonusers were assigned a value of 0 . Confounder variables were considered as independent variables.

The probit model is presented blew:

$\mathrm{CHI}_{\mathrm{i}}=\mathrm{b} 1+\mathrm{b}_{2}$ age $_{\mathrm{i}}+\mathrm{b}_{3}$ edu $_{\mathrm{i}}+\mathrm{b}_{4}$ gen $_{\mathrm{i}}+\mathrm{b}_{5}$ mar $_{\mathrm{i}}+\mathrm{b}_{6}$ inc $_{\mathrm{i}}+\mathrm{u}_{\mathrm{i}}$

Where age is the oldness of the people, edu is education level (5 levels from illiterate to university degree). Moreover, gen is the gender of people, mar is marriage status (three categories of married, divorced, widowed, and not married yet) and inc is the family's income.

After fitting a linear regression and finding the confounder variables, which had a significant effect on the dependent variable, the 2 groups of CHIs users and nonusers were matched based on the confounders. This matching estimator gives a single value to the whole confounder variables. The estimated values help to balance covariates within the strata and across the 2 groups. Nearest neighborhood method was used for comparison. Standard errors and t-statistic were used. The average treatment effect (ATT) results were presented for both after and before matching. We compared the out- ofpocket health spending, the number of dental services, general physician visits, hospital inpatient services, and medical emergency, nursing and midwifery, laboratory, specialists, pharmaceutical, and rehabilitation services in the 2 groups. Statistical significance was set at $\mathrm{p}<0.05$; and STATA 13 was used for data analysis. 


\section{Results}

Some descriptive statistics for the study are presented in Table 1. From 1354 participants, 812 (59.9\%) did not use complementary insurances and 542 (41\%) had CHI coverage. As demonstrated in Table 1, the mean age of the population was 36.8 years, average monthly income was 7435712 Rials, and the average out of monthly pocket health expenditure was 703941.6 Rials. Table 2 demonstrates the results of probit regression. Each of the variables, which had a significant relationship with the dependent variable were considered as confounders and were matched. As presented in the table, age, level of education, and income were not matched between the 2 groups; and to match the propensity scores, these variables had to be controlled between the 2 groups.

Table 3 demonstrates the results of $t$ tests and ATTs of the nearest neighborhood propensity scoring match between the 2 groups. Out- of- pocket health expenditures were not different between the 2 groups $(t=0.70)$. Thus, out- of- pocket health expenditures could not be reduced by using complementary health insurances. Similar results were found for general physicians' visits $(t=-0.44)$, emer- gency care utilizations $(\mathrm{t}=1.36)$, consulting services $(\mathrm{t}=1.03)$, nursing and midwifery services $(\mathrm{t}=-0.36)$, and rehabilitation services $(\mathrm{t}=-1.60)$. The differences were not significant in both unmatched and ATT results in these variables.

Without matching, utilization of hospital inpatient care services was not different between the 2 groups $(\mathrm{t}=1.29)$, while using a matching estimator revealed differences in hospital inpatient care utilization between CHIs users and nonusers $(\mathrm{t}=2.68)$. Similarly, specialists' visits were higher in those who used complementary insurance compared with others $(\mathrm{t}=2.01)$. In contrast, there were significant differences between the 2 groups in laboratory services using the unmatched method $(\mathrm{t}=2.07)$, while the results were not significant using ATT $(\mathrm{t}=1.15)$. By comparing the 2 groups, it was revealed that there were significant differences in both unmatched $(\mathrm{t}=5.82)$ and ATT $(\mathrm{t}=3.45)$ in using dental services between the 2 groups. All the significant relationships were positive, meaning that the average of utilization in people using complementary health insurances was higher than others.

Table 1. Descriptive Statistics

\begin{tabular}{|c|c|c|c|c|}
\hline Variable & Average & Standard deviation & Minimum & Maximum \\
\hline Age & 36.80738 & 15.49357 & 18 & 88 \\
\hline Monthly income & 7435712 & 6916157 & 0 & 100000000 \\
\hline Monthly Out- of- pocket payments & 703941.6 & 1998401 & 0 & 41000000 \\
\hline
\end{tabular}

Table 2. The Results of Probit Regression for Finding Confounder Variables

\begin{tabular}{|c|c|c|c|c|}
\hline Variable & Coefficients & Standard error & $\mathrm{z}$ & $\mathrm{p}$ \\
\hline Age (year) & 0.02 & 0.003 & 7.37 & $<0.001$ \\
\hline primary & 0.01 & 0.230 & 0.05 & 0.960 \\
\hline Secondary & 0.08 & 0.221 & 0.37 & 0.714 \\
\hline High school & 0.40 & 0.200 & 2.03 & 0.043 \\
\hline University degree & 0.85 & 0.205 & 4.15 & $<0.001$ \\
\hline divorced or widow & -0.03 & 0.141 & -0.25 & 0.805 \\
\hline not married & 0.09 & 0.097 & 1.00 & 0.316 \\
\hline Income & $1.73 * 10^{-07}$ & $5.53 * 10^{-08}$ & 3.13 & 0.002 \\
\hline Gender- female & 0.05 & 0.072 & 0.78 & 0.434 \\
\hline Constant & -1.90 & 0.276 & -6.89 & $<0.001$ \\
\hline
\end{tabular}

Table 3. The Results of Unmatched and Matched Methods in Comparing CHIs Users and Nonusers

\begin{tabular}{|c|c|c|c|c|c|}
\hline Variable & Comparing & Differences & Standard Error & T-statistics & $\mathrm{p}$ \\
\hline \multirow[t]{2}{*}{ Out- of- pocket expenditures } & Unmatched & 18199 & 11061 & 1.65 & 0.099 \\
\hline & ATT & 10811 & 15527 & 0.70 & 0.484 \\
\hline \multirow[t]{2}{*}{ General physician visits } & Unmatched & 0.0486 & 0.0456 & 1.07 & 0.284 \\
\hline & ATT & -0.027 & 0.0635 & -0.44 & 0.660 \\
\hline \multirow[t]{2}{*}{ Hospital inpatient care } & Unmatched & 0.020 & 0.0156 & 1.29 & 0.197 \\
\hline & ATT & 0.0387 & 0.0144 & 2.68 & 0.007 \\
\hline \multirow[t]{2}{*}{ Specialties } & Unmatched & 0.1640 & 0.0403 & 4.07 & 0.000 \\
\hline & ATT & 0.1146 & 0.0568 & 2.01 & 0.044 \\
\hline \multirow[t]{2}{*}{ Emergency care utilization } & Unmatched & 0.0005 & 0.0142 & 0.04 & 0.961 \\
\hline & ATT & 0.0147 & 0.0108 & 1.36 & 0.174 \\
\hline \multirow[t]{2}{*}{ Consulting Services } & Unmatched & 0.0208 & 0.0218 & 0.95 & 0.342 \\
\hline & ATT & 0.0295 & 0.0285 & 1.03 & 0.976 \\
\hline \multirow[t]{2}{*}{ Dental visits } & Unmatched & 0.2185 & 0.0375 & 5.82 & 0.000 \\
\hline & ATT & 0.1826 & 0.0529 & 3.45 & 0.005 \\
\hline \multirow[t]{2}{*}{ Nursing and midwifery } & Unmatched & 0.0151 & 0.0235 & 0.64 & 0.522 \\
\hline & ATT & -0.0117 & 0.0326 & -0.36 & 0.718 \\
\hline \multirow[t]{2}{*}{ Rehabilitation services } & Unmatched & 0.0226 & 0.0564 & 0.40 & 0.689 \\
\hline & ATT & -0.1752 & 0.1098 & -1.60 & 0.109 \\
\hline \multirow{2}{*}{ Laboratory services } & Unmatched & 0.07115 & 0.0343 & 2.07 & 0.038 \\
\hline & ATT & 0.05166 & 0.0450 & 1.15 & 0.250 \\
\hline
\end{tabular}




\section{Discussion}

No differences were found between the 2 groups in outof- pocket health expenditures. Moreover, expenditures had 2 characteristics: (1) the payment for health services, and (2) the number of services. Under the coverage of CHIs, the payment for each service will be diminished, but the number of consumed services will be increased. In this study, these 2 contradictory effects did not lead to significant variations in health expenditures. From the ability to pay approach, the ability to pay for health services was stable whether people had complementary insurance or not. Therefore, people pay the same amount of money when they are covered by complementary insurance. This confirmed the effects of unsatisfied needs for health services. From the public health approach, by using CHIs, the ability to pay for health care services would increase and people can use more services. Thus, the CHIs cover those parts of health need which people were not able or desired to pay for. In a study done by Chu et al. in Taiwan, authors found that using national health insurance would reduce out- of- pocket by approximately $23.08 \%$ (18). In another study in Mexico, the authors found the effects of Seguro Popular (SP) health insurance on the expenditures of the poor. They concluded that outpatient and medicine expenditures were lower when people used the SP program (19). Aji et al., using panel data of Indonesia, found that from 3 health insurance programs, 2 significantly reduced out- of- pocket health expenditures (20).

General physicians' visits (GPs) was not different between CHI covered people and others; however, hospital and inpatient services' visits were higher for those who were covered by complementary insurances. GP services have a low price elasticity $(2,21)$. Using CHIs will decrease the prices for users, but because of the low price elasticity, decreasing in prices do not change the size of consumption. As a result, no alterations were shown in utilization of GP visits. The price elasticity of specialist visits is higher than that of GPs, however, the probability of using specialist services will increase when using CHIs $(2,3)$. In addition, the stability of GPs service usage and the increases in specialist services in CHIs indicated a shift of patients from GPs visits to the specialists. So, the quantity of service usage increased and at the same time the quality of services used by CHI users was higher than the nonusers. Thus, the CHIs helped people to use high quality services. However, the results revealed that the utilization of GP visits did not change after using CHIs, but it is important to increase complementary health insurance, especially for the poor who cannot buy general physicians health services. GP visits must be available for all groups regardless of their income. CHIs are the best way to increase access to GP services. In a study done by Lind et al. in the United States, the authors compared the complementary insurance users (CAM) and nonusers. Similar to our findings, they found that outpatient expenditures were higher in CAM users, while the cost of inpatient and imaging services were lower (22). Devlin et al. in a study using latent-class model in Canada found that supplementary insurance changed the number of physi- cians' visits by individuals, but these changes were different between those who were less ill and those with severe diseases (23). In a study done by Trujillo in 2005, authors compared utilization of health services in Colombia's health insurance program in the poor. Similar to this study, they used propensity scoring marching method. They divided the population into 5 age groups and compared the results. They found that outpatient visits were different in the insured population, compared with the uninsured. Also, hospital services usages were higher in females and children under 5 years (24). Jeon et al. in Korea found that the probability of any health care utilization, both inpatient and outpatient care, was higher in primary health insurance users in comparison with others (25). Also, the French evidence showed that physician service utilization was higher in those using health insurances and CHIs (5). Chilean results showed that using health insurance increased hospitalization negligibly, but the relationship was not significant for medical visits (26).

Dental services usages were higher in CHIs. Main Iranian health insurances do not cover dental services, but CHIs cover some of them. Dental services have very high price elasticity, and only a small decrease in the prices will increase the number of dental visits. The difference between CHIs users and nonusers could be justified by the high price elasticity $(2,27)$. Unlike specialist visits, which could be substituted with GPs services, there is no substitute for dental services. Patients with dental problems do not have any other options if they do not want to join CHIs and they must pay for the expensive dental services. Arinen et al. in a study in Finland found that dental expenditures were higher after a subsidization reform(28). Similar results were also found by Eriksson in Turku, Finland (29). We did not find any significant differences between the 2 groups in laboratory tests. Chen et al. in a study in Taiwan found that complicated laboratory tests were increased in the new insurance coverage in pregnant women (30). Also, consultation services did not change in $\mathrm{CHI}$ users. They also found that the proportion of pregnant women who received consultation services was constant, but family planning consultation services declined (30). In addition, no significant differences were found in rehabilitation services and emergency services; these services are categorized as low price elastic services (2). In this study, we measured the differences between CHIs users and nonusers in an urban region, where access to health care was easier. Despite the differences between the need and demand, from the public health approach, high demand price elastic services are not as necessary as the low demand. Dental services and laboratory services have high demand price elasticity, but GP visits and prehospital services have low demand price elasticity. Insurance coverage of low price elastic services is vital for increasing the health of the general population. Using CHIs for low price elastic services can improve equality in use of these services among the rich and the poor and can also improve access to services. This study presented some evidence about the effects of complementary health insurance on utilization of services. This study has been done in an urban region and the results could not be extended to the 
country. For future studies, it is suggested to include both urban and rural regions to compare the probable differences.

\section{Conclusion}

No significant differences were found between the 2 groups in out- of- pocket health expenditures. However, utilization of dental, hospital inpatient and specialist services was different between the 2 groups. This could be justified by the stability of ability to pay for health care services. People did not change their budget share for health care services after using CHIs. However, the prices of services decreased after using CHIs, but because of increasing the quantity and quality of services, they paid equal to people who were not CHIs users. Shifting from general physician visits to specialists' visits was observed in CHIs users and nonusers. Higher quality services were available to use through CHIs.

\section{Conflict of Interests}

The authors declare that they have no competing interests.

\section{References}

1. Kifmann M. Risk selection and complementary health insurance: The Swiss approach. Int J Health Care Finance Econ. 2006;6(2):151-70.

2. Getzen TE. Health economics: fundamentals and flow of funds: John Wiley \& Sons New York; 1997.

3. Henderson J. Health Economics and Policy (with Economic Applications): Cengage Learning; 2011.

4. Witter S, Ensor T, Thompson R, Jowett M. Health Economics for Developing Countries. A Practical Guide: MacMillan Education; 2000.

5. Buchmueller TC, Couffinhal A, Grignon M, Perronnin M. Access to physician services: does supplemental insurance matter? Evidence from France. Health Econ. 2004;13(7):669-87.

6. Halpern MT, Renaud JM, Vickrey BG. Impact of insurance status on access to care and out-of-pocket costs for US individuals with epilepsy. Epilepsy Behav. 2011;22(3):483-9.

7. Einav L, Finkelstein A, Ryan SP, Schrimpf P, Cullen MR. Selection on moral hazard in health insurance. National Bureau of Economic Research; 2011.

8. Gulliford M, Morgan M. Access to health care: Routledge; 2013.

9. Sari AA, Rezaei S, Rad EH, Dehghanian N, Chavehpour Y. Regional disparity in physical resources in the health sector in Iran: a comparison of two time periods. Iran $\mathbf{J}$ Public Health. 2015;44(6):848.

10. Xu K, Evans DB, Kawabata K, Zeramdini R, Klavus J, Murray CJ. Household catastrophic health expenditure: a multicountry analysis. The lancet. 2003;362(9378):111-7.

11. Hwang W, Weller W, Ireys H, Anderson G. Out-of-pocket medical spending for care of chronic conditions. Health Aff. 2001;20(6):26778.

12. Mohtasham-Amiri Z, Jafari-Shakib A, Khalili-Moosavi A. Prevalence and factors associated with Ecstasy use among college undergraduates in north of Iran-2005. Asian Journal of Psychiatry. 2011;4(1):31-4.

13. Davari M, Haycox A, Walley $T$. The Iranian Health Insurance System; Past Experiences, Present Challenges And Future Strategies. Iran J Public Health. 2012;41(9):1-9.

14. Iran Minstry of Health and Medical Education. Health Insurance Coverage. In: MOH, editor. Tehran; 2014.

15. World Bank Group. Out- of- pocket Health Expenditures. In: Bank W, editor. Geneva: World Bank Publications; 2014.

16. Newhouse JP. Insurance benefits, out-of-pocket payments, and the demand for medical care: a review of the literature: Rand Corporation; 1978.

17. Rad EH, Tavakkoli M, taghi Moghadamnia M, Ghanbari A. Fertility and Minority: A Study in Two Provinces of Iran Using Matching Estimator Technique. Journal of Immigrant and Minority Health. 2016;18(3):660-5.

18. Chu TB, Liu TC, Chen CS, Tsai YW, Chiu WT. Household out-ofpocket medical expenditures and national health insurance in Taiwan: income and regional inequality. BMC Health Serv Res. 2005;5(1):60.

19. Galárraga O, Sosa-Rubí SG, Salinas-Rodríguez A, Sesma-Vázquez S. Health insurance for the poor: impact on catastrophic and out-ofpocket health expenditures in Mexico. Eur $\mathrm{J}$ Health Econ. 2010;11(5):437-47.

20. Aji B, De Allegri M, Souares A, Sauerborn R. The Impact of Health Insurance Programs on Out-of-Pocket Expenditures in Indonesia: An Increase or a Decrease? Int $\mathrm{J}$ Environ Res Public Health. 2013;10(7):2995-3013.

21. Arefnezhad M, Yazdi Feyzabadi V, Homaie Rad E, Sepehri Z, Pourmand S, Rava M. Does Using Complementary Health Insurance Affect Hospital Length of Stay? Evidence from Acute Coronary Syndrome Patients. Hospital Practice. 2016;44(1):28-32.

22. Lind BK, Lafferty WE, Tyree PT, Diehr PK. Comparison of health care expenditures among insured users and nonusers of complementary and alternative medicine in Washington state: A cost minimization analysis. J Altern Complement Med. 2010;16(4):411-7.

23. Devlin RA, Sarma S, Zhang Q. The role of supplemental coverage in a universal health insurance system: Some Canadian evidence. Health Policy. 2011;100(1):81-90.

24. Trujillo AJ, Portillo JE, Vernon JA. The impact of subsidized health insurance for the poor: evaluating the Colombian experience using propensity score matching. Int $\mathrm{J}$ Health Care Finance Econ. 2005;5(3):211-39.

25. Jeon B, Kwon S. Effect of private health insurance on health care utilization in a universal public insurance system: A case of South Korea. Health policy. 2013;113(1-2):69-76.

26. Sapelli C, Vial B. Self-selection and moral hazard in Chilean health insurance. J Health Econ. 2003;22(3):459-76.

27. Sintonen H, Linnosmaa I. Economics of dental services. Handbook of health economics. 2000;1:1251-96.

28. Arinen S, Sintonen H, Rosenqvist G. Dental utilisation by young adults before and after subsidisation reform in Finland: University of York, Centre for Health Economics; 1996.

29. Tuominen R, Eriksson AL. A study on moral hazard in dentistry: costs of care in the private and the public sector. Community Dent Oral Epidemiol. 2011;39(5):458-64.

30. Chen LM, Wen SW, Li CY. The impact of national health insurance on the utilization of health care services by pregnant women: the case in Taiwan. Matern Child Health J. 2001;5(1):35-42. 